\title{
Avaliação da atividade antibacteriana do araçá (P. guineense) sobre o desenvolvimento de Enterococcus Faecalis
}

Kátia Aparecida FRANCISCO ${ }^{1}$

Alexandre Tourino MENDONÇA²

\begin{abstract}
${ }^{1}$ Graduada em Odontologia pela Universidade Vale do Rio Verde (UNINCOR), Cirurgiã Dentista, aitakaf@gmail.com
${ }^{2}$ Doutor em Ciências dos Alimentos pela UFLA/Professor, membro do Comitê de Ética em pesquisa e Assessor de Pesquisa da UNINCOR, alexandretourino@gmail.com
\end{abstract}

Recebido em: 05/05/2015 - Aprovado em: 13/07/2015 - Disponibilizado em: 15/07/2014

\begin{abstract}
RESUMO
Estudou-se a atividade antibacteriana da planta (P.guineense) em relação ao hospedeiro E. faecalis, um tipo de bactéria encontrada no tracto digestório e até mesmo em canais radiculares. $\mathrm{O}$ grande desafio dos cirurgiões dentistas é o insucesso dos tratamentos endodônticos causados pela permanência do E. faecalis nos tubos dentinários. Com base em relatos de pessoas que ingeriram (P.guineense) por um determinado período e de pesquisas cientificas que constataram na planta a existência de componentes capazes de reduzir a proliferação bacteriana, realizou-se uma avaliação do extrato do vegetal. Foram colhidas folhas novas e velhas e os extratos elaborados foram diluídos em concentrações de $0 \%, 1 \%, 5 \%, 10 \%, 25 \%$, e 50\%, diluídas em álcool 70. Posteriormente, foram colocadas sobre uma placa de Petri como meio de cultura. Na amostra, as folhas novas inibiram mais se comparadas com as folhas velhas. Em relação às concentrações, as soluções de baixa concentração demonstraram um resultado mais significativo se comparada com as soluções de alta concentração.
\end{abstract}

Palavras-chave: extrato de araçá.resistência bacteriana. endodontia. tubosdentinários. concentrações.

\section{EVALUATION OF ANTIBACTERIAL ACTIVITY OF ARAÇÁ (Guinean P.) ON THE DEVELOPMENT OF ENTEROCOCCUS FAECALIS}

\begin{abstract}
It was studied the activity of theantibacterial plant (P.guineense) to the host E. faecalis, one type of bacteria found in the digestive tract and even in root canals. The challenge of dentists is the unsuccessful endodontic treatments caused due to the permanence of E. faecalis in the dentinal tubes. Based on reports from people who ate (P.guineense) for a certain period and scientific research that demonstrated the existence of the plant components capable of reducing bacterial proliferation, it was performed an evaluation of the vegetable extract. Young and old leaves were harvested and diluted extracts were prepared at concentrations of $0 \%, 1 \%, 5 \%, 10 \%, 25 \%$ and $50 \%$, diluted in alcohol 70 . Later they were placed on a Petri dish as a growth medium. In the sample, the new leaves inhibited more compared to old leaves. Regarding the concentration, solutions of lower concentration showed a more significant results if compared with the high concentration solutions.
\end{abstract}

Keywords: extract of araçá.bacterial resistance.endodontics.dentinal tubes. concentrations.

\section{Introdução}

E. faecalis são bactérias Gram-positivas e normalmente infectam o tracto gastro-intestinal, corrente sanguínea, endocárdio e canal radicular. Na odontologia este tipo de bactéria está diretamente relacionado com o insucesso no tratamento endodôntico, e como consequência causam doenças perirradiculares [Nacif et Al, 2010]. Este tipo de bactéria apresenta capacidade de penetração pelos tubos dentinários, tornando-as sobreviventes durante o preparo químico-mecânico do conduto radicular. Por este motivo, após a obturação do canal, a bactéria poderá invadir o conduto e 
infectá-lo novamente. Os microrganismos sobrevivem dentro dos tubos devido à presença de colágeno e permitem sua adesão [Love, 2001]. Outro fator é a alta virulência, decorrente da persistência bacteriana após inserção de medicamentos intra-radicular utilizado durante procedimento endodôntico.

Com objetivo de elaborar uma solução antimicrobiana com a finalidade de erradicar os microorganismos relutantes encontrados na estrutura dentária, e após as terapias propostas, utilizou-se o extrato do araçá para avaliar sua atividade antibacteriana.

$\mathrm{O}$ araçá Psidium pertence à família Myrtaceae e possui cerca de cento e dois gêneros e de três mil e vinte quatro espécies. Espécies Psidium, vulgarmente conhecida como araçá, estão distribuídas em regiões da América onde a vegetação de campos e cerrado são predominante. No Brasil, este tipo de vegetação está localizado nas regiões centro-oeste, sudeste e em parte do sul [Avidos et Al, 2000].

Tradicionalmente, as plantas de Psidium spp. são usadas para tratar o escorbuto na Ásia e África, para tratar a tosse e doenças pulmonares na Bolívia e no Egito, como um agente antiinflamatório hemostático na China e como um composto anti-diarréia no México. O araçá apresenta composição ácida fenólica, com alto potencial antioxidante, que são empregados na conservação de alimento e na ação de neutralização dos radicais livres gerados pelo organismo, que estão associados com carcinoma e doenças cardiovasculares. Particularmente, a atividade dos flavonoides é provavelmente devido à sua capacidade para formar complexos com proteínas extracelulares e solúveis e com paredes de células bacterianas; taninos são capazes de inativar proteínas através da formação de complexos irreversíveis que podem levar à perda de função de adesinas microbianas, enzimas, proteínas de transporte do envelope celular [Brighenti et Al, 2008]. Além disso, verificam-se bons teores de cálcio, ferro, fosforo e vitaminas A, B, C, proteínas e carboidratos.

As plantas contêm diversos componentes dispersos por suas estruturas, sendo assim, busca-se aperfeiçoar estes recursos para que eles sejam usufruídos de forma benéfica para o homem.

O extrato do araçá foi elaborado a partir de indícios relatados por um membro que habitava na zona rural. Este relatou não ter utilizado escovas dentais, dentifrícios e se quer o fio dental durante a infância, porém ingeria constantemente frutas típicas do cerrado como araçá, além de não consumir açúcar diariamente. Até os 12 anos não apresentavam lesões cariosas, o que foi constato apenas quando realizou a sua primeira consulta ao cirurgião dentista. Com base neste relato, foi preparado o extrato da folha de araçá para 
análise antimicrobiana e foi utilizada como hospedeiro a bactéria E. faecalis.

Figura 1 - Imagem ilustrativa da planta araçá

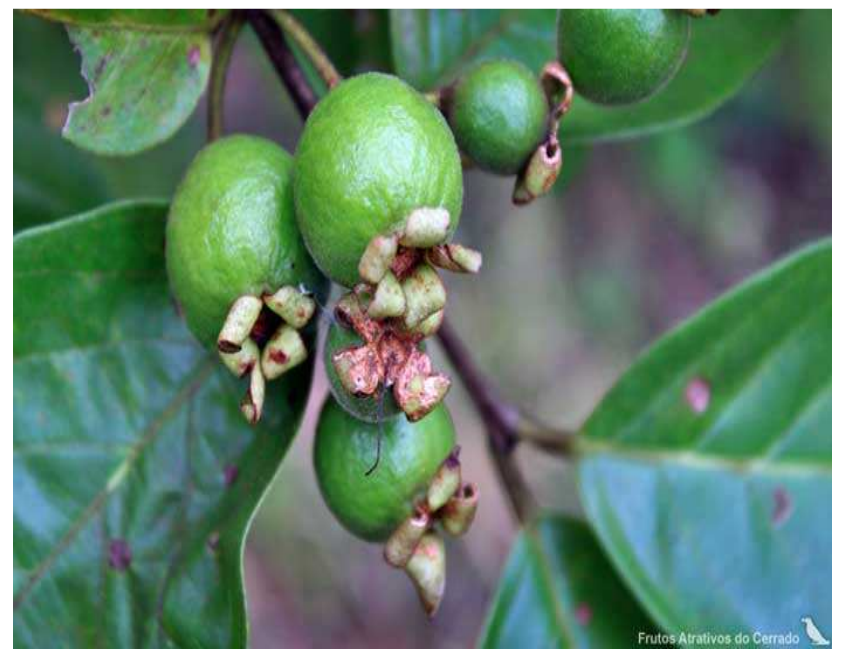

Fonte: http://www.frutosatrativosdocerrado.bio.br

\section{Materiais e Métodos}

Foram colhidas e embaladas separadamente as folhas novas $(\mathrm{FN})$ e velhas $(\mathrm{FV})$ do araçá $(\mathrm{P}$. guineense), no período da manhã na cidade de Minduri-MG, durante o mês de agosto de 2011 e posteriormente, armazenadas em um saco plástico desprovido de luminosidade, e mantido em uma temperatura entre $3^{\circ}$ a $5^{\circ} \mathrm{C}$ até o exato momento da retirada do extrato. Foram pesadas as FN separadamente das FV sendo $100 \mathrm{~g}$ de cada folha para cada $170 \mathrm{ml}$ de álcool a $70 \%$. Feita a pesagem, foi obtido o extrato através de maceração. Após a maceração, as amostras foram filtradas e conduzidas em um recipiente de vidro com capacidade de $1000 \mathrm{ml}$ cada um, hermeticamente fechados, sendo em seguida protegidos da luz e conservados a uma temperatura de aproximadamente $15^{\circ} \mathrm{C}$. Permaneceram durante sete dias com agitação diária do conteúdo por três minutos, a fim de diminuir a viscosidade do líquido. Após o período de uma semana, as amostras foram retiradas dos recipientes fechados e dispensadas em um refratário aberto e levado a uma estufa em uma temperatura estável de $50^{\circ} \mathrm{C}$, onde permaneceram durante 96 horas.

Observou-se que o extrato das FN tornaram-se mais viscosos, se comparado ao das FV. Assim foi recolhido o refratário que continham as FN e permaneceram as FV por mais 24 horas até obterem a consistência semelhante ao do extrato retirado anteriormente.

Os meios de cultura empregados para promover o crescimento bacteriano foram Tryptic Say Agar (TSA) e Mikrobiologie. Elaborou-se as proporções de $8 \mathrm{~g}$ TSA em $200 \mathrm{ml}$ de água e 1,5g Mikrobiologie em 40ml de água. Após a manipulação dos meios de cultura e efetuado a esterilização das placas de Petri, inseriu-se os compostos nutritivos, os quais foram resfriados no período de 48 horas, juntamente com os E. faecalis. Finalmente foram inoculados sobre a placa seis diferentes tipos de concentrações do extrato de araçá, sendo $0 \%, 1 \%, 5 \%, 10 \%$, $25 \%$, e 50\%, diluídas em álcool $70 \%$. [Mendonça, 2004] 
Gráfico 1 - Análise de concentrações dos extratos de folhas velhas e novas

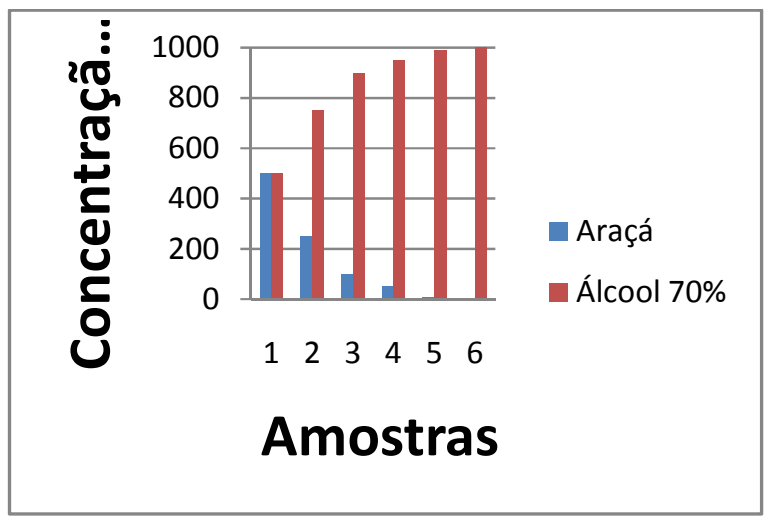

Fonte: Autoria própria.

\section{Discussão}

Alguns estudos analisam atividade terapêutica do Psidium spp. na odontologia. A ação terapêutica do extrato tem como objetivo avaliar a capacidade de combater determinadas patologias que ainda são um desafio para ciência, seja por falta de conhecimento de sua etiologia ou por mutações bacteriana e virótica que promovem sua reincidência [Jebashree et $\mathrm{Al}, 2011]$.

Apesar da inovação tecnológica na produção de aparelhos rotatórios e reciprocantes durante o preparo mecânico atingindo o limite do ápice radicular, promovendo a desinfecção, estes avanços não foram suficiente para garantir a eficácia da irradicação bacteriana [7, 8]. Atualmente o hipoclorito de sódio a $5 \%$ é um dos líquidos mais utilizados para preparo químico, porém sua ação pode não ser efetiva [Giles et $\mathrm{Al}, 2010]$. Isto se deve a penetração das E. faecalis nos tubos dentinário. Após obturação do canal, as bactérias retornam ao canal, contaminando e promovendo lesões periápice [Mickelet Al, 2003]. Esta bactéria tem um alto poder virulento o que impede sua destruição.

Em um estudo sobre o extrato de Psidium cattleianum [Brighenti et Al, 2008], este apresentou um efeito significante antibacteriano sobre a bactéria S. mutans. Desta forma, o extrato pode ser utilizado para a prevenção da cárie dentária.

Outro estudo cientifico [Crivelaro et Al, 2010] demostrou que o os extratos testados tiveram um efeito significativo sobre a bactéria $S$. mutans no biofilme oral dos ratos, diminuindo sua acumulação. De acordo com as pesquisas, Psidium spp. contém uma substância capaz de reduzir a proliferação bacteriana. Ambos os estudos citados anteriormente [Brighenti et Al, 2008] e [Crivelaro et Al, 2010] apresentaram uma redução significativa das bactérias. Com base nos resultados, conclui-se que a planta revela um poder antibacteriano. Desta forma o extrato pode ser utilizado futuramente como uma alternativa para adequação do meio bucal impedindo a proliferação de determinada patologias bucais.

\section{Resultados}

Os resultados das analises microbiológicas mostraram que os extratos de folhas velhas 
obtiveram o melhor potencial de inibição bacteriana se comparados com as folhas novas. Entre o grupo de folhas velhas a concentração de $5 \%$ de araçá foram as que mais impediram o crescimento microbiano verificado em concentrações de $0 \%$ e $1 \%$ de araçá. Verificouse também outro fator relevante; utilizando apenas a concentração de $100 \%$ de álcool 70 não houve inibição expressiva das bactérias, algo que foi constatado na concentração de $95 \%$ de álcool 70 e 5\% de araçá. Desta forma permite-se concluir que o extrato do (Psidium guineense) apresenta uma ação inibidora que atua em baixas concentrações nas folhas novas.

Figura 2 - Cultura do E. faecalis em presença do extrato de araçá

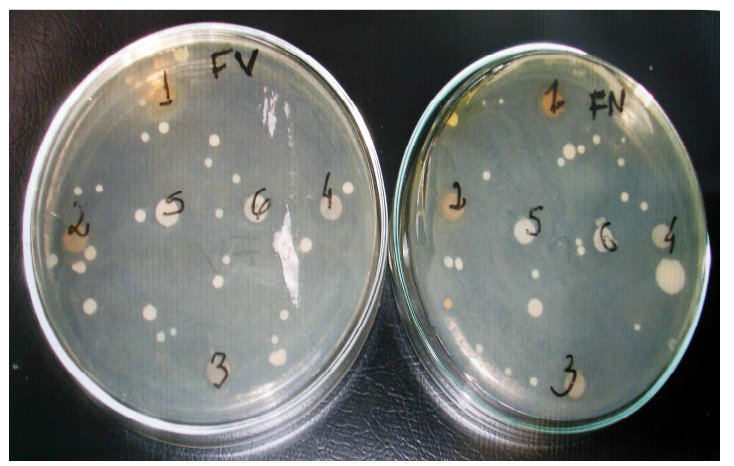

Fonte: autoria própria.

\section{Referencias Bibliográficas}

Avidos, Maria Fernanda Diniz, and Lucas Tadeu Ferreira. "Frutos dos Cerrados." Preservação gera muitos (2000).

Brighenti, F. L., et al. "Effect of Psidium cattleianum leaf extract on Streptococcus mutans viability, protein expression and acid production."Caries research 42.2 (2008): 148154.

Crivelaro de Menezes, Tais Elisabete, et al. "Protective efficacy of Psidium cattleianum and Myracrodruon urundeuva aqueous extracts against caries development in rats." Pharmaceutical biology 48.3 (2010): 300305 .

Giles, L. H., et al. "The efficacy of different endodontic irrigants against Enterococcus faecalis in an extracted human tooth model. "International Endodontic Journal 43.4 (2010): 353-353

Love, R. M. "Enterococcus faecalis-a mechanism for its role in endodontic failure." International Endodontic Journal 34.5 (2001): 399-405.

Jebashree, H. Shyla, et al. "Antimicrobial activity of few medicinal plants against clinically isolated human cariogenic pathogens - An in vitro study." ISRN dentistry 2011 (2011).

Mendonça, Alexandre Tourino "Efeito dos óleos essenciais de condimentos sobre o crescimento Staohylococcus aureus em ricota cresmosa“ Lavras: UFLA, 2004 Tese (Doutorado).

Mickel, André K., Tuan H. Nguyen, and Sami Chogle. "Antimicrobial Activity of Endodontic 
Sealers on Enterococcus faecalis." Journal of Endodontics 29.4 (2003): 257-258.

Nacif, Marcia Christina André Moreira, and Flávio Rodrigues Ferreira Alves. "Enterococcus faecalis na Endodontia: um desafio ao sucesso." Rev. bras. odontol 67.2 (2010): 20914.
Sedgley, Christine, Gwendolyn Buck, and Oliver Appelbe. "Prevalence of Enterococcus faecalis at Multiple Oral Sites in Endodontic Patients Using Culture and PCR." Journal of endodontics 32.2 (2006): 104-109.

http://www.frutosatrativosdocerrado.bio.br/76especies. Acesso em: 01 de novembro de 2014. 